\title{
Analysis of the Legal Awareness of Public, Industry Association and Government during the Implementation of Environmental Law-Taking the comparison of disposable foam tableware and PX project as examples
}

\author{
Hongjuan Chen ${ }^{1,2, a}$, Jinshui Yao ${ }^{1, b}$ and Lin Zhao ${ }^{2, c *}$ \\ ${ }^{1}$ Qilu University of Technology(Shandong Academy of Science),Jinan,China \\ ${ }^{2}$ School of Environmental Science \& Engineering,Tianjin University, Tianjin,China \\ achj@qlu.edu.cn, byaojsh@qlu.edu.cn, czhaolin@tju.edu.cn \\ ${ }^{*}$ Corresponding author
}

Keywords: Environmental law, PX project, Disposable foam tableware

\begin{abstract}
The legal awareness of public, industry association and government was analyzed by using two events, i.e the PX project and the disposable foam tableware about environmental law in China, as examples.From these two environmentally related events, it is not difficult to find out that when it comes to implementing the environmental protection law or handling environmental protection events, there is a lack of a mature, rational and comprehensive way of recognition and doing things for individuals, groups like industry associations, and even government departments. There is a pressing demand for enhancing and promoting environmental protection awareness in China. The environmental protection law is provision and foundation, but it should never become an excuse or a guise.
\end{abstract}

\section{Introduction}

China has already proposed the slogan "Lucid water and lush mountains are invaluable assets". With this background, the implementation of environmental laws including the Environmental Protection Law and the Law on the Prevention and Control of Air Pollution has received unprecedented attention[1,2]. Especially since the 18th National Congress, the phenomenon of "poor implementation" of the Chinese environmental law, which has been criticized by scholars and the public, has slowly changed[3]. The ecological environment in China is constantly improving. However, due to the "difficulty in reforming", our ecological environment still needs to be improved, and the environmental awareness of all levels of government and the public still need to be enhanced.

Since our local governments have placed more emphasis on GDP assessment indicators in previous years, environmental law has been weakened or replaced by various economic policies. The enforcement of environmental law has also been strongly resisted by local governments. Moreover, due to political reasons in previous years, the public tends to stand against the government when it comes to environmental protection. This article takes two important environmental events as examples to analyze the current environmental and legal awareness of the public, industry association, and government in China.

In 1999, the Economic and Trade Commission and the National Development and Reform Commission listed disposable foam tableware in the category of eliminated products and prohibited its production, sale, and use. This decision was later reaffirmed in 2005 and 2011. However, in 2013, the National Development and Reform Commission removed foam plastic tableware from the category of eliminated products, which meant that the disposable foam tableware was lifted after being banned for 14 years. These two events of the ban and lifting of disposable foam tableware have not attracted much public attention. In sharp contrast, the public has an intense or even extreme reaction when it comes to the approval of chemical-related projects, such as PX projects in different places. 


\section{Analysis of the legal awareness of every group in the PX project in China}

\subsection{The attitude of government and public}

Taking the PX (p-xylene) project as an example, there have been many environmental group incidents against this kind of chemical construction projects across the country in recent years, such as the PX incident in Xiamen in 2007, Dalian in 2011, Zhenhai of Ningbo in 2012, Kunming in 2013 and Maoming in 2014. Basically, the construction has been either moved or stopped due to protests of local citizens. On the positive side, many environmental or legal experts believe this has shown a gradual improvement in Chinese people's environmental awareness. They even consider this as a typical example of actively participating in the maintenance of environmental law. The earliest Xiamen PX incident has even been widely recognized as the "milestone" of Chinese people's participation in environmental protection, and a "classic example of the interaction between the government and the people". On the other side, these incidents are negative examples of interfacing with government decisions by abnormal measures. Under the guise of environmental protection, the public has demonized the PX project without even understanding the real harm of it[4].

\subsection{The attitude of the experts' groups}

Regarding environmental issues around chemical projects, it seems that industry associations do not have much influence. In fact, apart from the public and the government, there have always been two groups fighting against each other around the toxicity and environmental pollution of the PX project. One is a group of so-called chemical experts representing chemistry and chemical experts. The other is a group of so-called environmental experts representing the supremacy of environmental protection. These two groups have repeatedly revised the PX entry on Baidu. One said that PX was almost nontoxic and even equivalent to alcohol. The other said it was highly toxic and could cause cancer. Both sides' views were based on the environmental protection law, but one said PX had almost no impact on the environment and the human body. The other said PX had an immeasurable impact on the environment and the human body. Obviously, both views were one-sided and too extreme. However, the former was more likely to be regarded as the spokesperson of the government. The PX project should be constructed if there was no environmental pollution, toxicity or direct harm to the human body. The latter was more likely to be regarded as the spokesman of the local people, who believed that the construction had to be stopped or changed for the sake of themselves and future generations.

\subsection{The analysis of the legal awareness of every groups}

By carefully analyzing such incidents, it is not difficult to find that under the background of environmental protection, or under the cover of the environmental protection law, the legal awareness of parties involved has greatly improved compared to the past, which is good news for changing the current situation of poor implementation of the environmental protection law in China. However, by analyzing more deeply, it is also not difficult to discover that both parties are standing on opposite sides to debate and argue with the other. In this process, the radical emotion has replaced rational thinking. People exaggerate the other side's point for the benefit of their own with no concern for the other side's view, leading to two extremes with no possibility of coordination. In fact, PX is neither highly toxic nor non-toxic. No one can confirm that PX will or will not cause cancer. In addition, pollution or toxicity of long-term contact and short-term exposure is not the same. Objectively speaking, if right approaches have been taken and all aspects of the project are strictly in line with national policies or environmental department's requirements, there is no need to worry about followup problems. But PX is definitely not just as toxic as alcohol like the chemical experts claimed.

As for the PX projects mentioned above, some were suspended, while others were relocated to other places. Those living near the relocation were either not too excited about this, or not excited enough to influence the decision, and the project was launched anyway. Those living near the original location achieved their aim of no PX near their living places and stopped arguing. This further indicates that parties involved in PX incidents have not rationally and objectively analyzed the PX substance based on relevant laws like the environmental protection law. They only fight for their own interests. 


\section{Analysis of the legal awareness of every group in the lifting of disposable foam tableware}

The manifestation of this so-called awareness of environmental protection that exists among the public and groups further confirms the author's point when it comes to the ban and lifting of disposable foam tableware, which influences almost every family and everyone.

\subsection{The background of the banning and lifting of foam disposable tableware}

It is well known that nearly every family and everyone use disposable tableware, so it seems that the ban and lifting of disposable foam tableware should be a concern of ordinary people. Especially when people's environmental awareness has gradually strengthened after 14 years, this important decision of the National Development and Reform Commission should have raised heated debate among various groups and ordinary people. However, it seems that ordinary people do not care about this. When the National Development and Reform Commission made the decision to officially lift the ban on disposable foam tableware from May 1, 2013, experts in food packaging had exclaimed that "the lifting of disposable foam tableware will seriously damage people's growing enthusiasm on environmental protection". However, this event only caused disputes between two industry associations representing their own interests, one was the plastics industry association who urged to lift the ban, the other was the food packaging industry association against the lifting.

A fact people may not know is that the reason behind the National Development and Reform Commission's ban on disposable foam tableware in 1999 is the white pollution that is difficult to be completely recovered. This is also a problem of all the other plastics. But disposable foam tableware itself is white, and it is lightweight, large in quantity, and difficult to recycle, making it the pioneer in white pollution. The previous ban on this product was not because of backward technology, high energy consumption, or potential toxicity. Disposable foam tableware actually has many advantages, it is light, durable, easy to shape and process. Western developed countries usually adopt measures like the restriction on the production and legally enforced recycling, none of these countries has completely banned production like China. Due to the growing demand for disposable tableware, alternatives must be found if foamed polystyrene (EPS) is to be banned. During these 14 years, two materials have been considered to be possible substitutes for EPS. One is the so-called degradable disposable tableware, which is actually semi-degradable plastic made of starch-grafted polyethylene. The starch is degradable, but the remaining polyethylene is non-degradable. In addition, the degradation of starch will change the remaining polyethylene to smaller pieces, making it more difficult to recycle. This material is only self-deceptively degradable, it is expensive, and performs far worse than EPS. Another possible substitute is the paper product, which is considered to be completely green and environmental-friendly, but this cannot bear closer analysis. The biggest problem is that the performance of paper products is too bad, these products cannot bear weight or hold food for a long time. Moreover, the paper has good absorption of water and is highly hydrophilic. To hold food, the paper must be hydrophobically treated with hydrophobic materials. This thin layer is more difficult to recycle and has safety concerns, but these problems have not raised attention among all levels and consumers. Another problem is that though the paper is green and environmental-friendly, the production of paper will bring enormous pollution and consume a large amount of wood. The industry chain as a whole cannot be considered green. Therefore, from perspectives of energy and environmental protection, it is difficult for both alternatives to truly replace the original EPS.

It is precisely because of the above-mentioned reasons that in the 14 years of the complete prohibition of production, disposable foam tableware made of EPS material had not really disappeared from China. Many small shops continued the massive use. Its good cost performance brought huge benefits to enterprises that had secretly produced, thus seriously affecting the normal market order. It might be because of such considerations that the National Development and Reform Commission moved from one extreme to another and had completely freed the production. Both the ban in 1999 and the lifting in 2013 lack a comprehensive and balanced consideration that should be possessed by any mature government or department. This is obviously different from the rational legislative work in Western developed countries[5]. 


\subsection{The attitude of the two industry associations}

If we review the behaviors of the two industry associations that have stood on opposite sides when the disposable foam tableware was lifted in 2013, the same way of thinking as the two groups in the PX incidents can also be found everywhere. The plastics industry association supports the lifting because it will clearly promote the development of the plastics industry. But the association has not provided the government or the legal department with any reasonable fundamental solution to the white pollution problem that will definitely be caused by the lifting. Meanwhile, the food packaging industry association's strong objection is not because of the concern of white pollution, but more of its negative stereotype image of plastics. It is believed that plastic must contain the toxic plasticizers so that plastic must be toxic. If it is used for food packaging the food will be contaminated. The conclusion is that the disposable foam tableware cannot be lifted. In fact, several old cases of food plasticizers exceeding the standard have all been blamed on plastic. It is necessary to point out that plastic and plasticizers are not the same and not all plasticizers are toxic. Food-related cases of excessive plasticizers are not caused by plastic. We will discuss this in future articles.

\subsection{The attitude of the public}

For bottom-level consumers, although almost everyone is affected and white pollution is a major social problem, there will not be any immediate impact on individuals. Most people do not know whether it is toxic or not, and they do not have professional knowledge. This is unlike the construction of a PX project near someone's home, which will affect the health of individuals, families and even future generations. Therefore, ordinary people do not care much about the disposable foam tableware.

\section{Conclusion}

From these two environmentally-related events that happen around us, it is not difficult to find out that when it comes to implementing the environmental protection law or handling environmental protection events, there is a lack of a mature, rational and comprehensive way of recognition and doing things for individuals, groups like industry associations, and even government departments. There is a pressing demand for enhancing and promoting environmental protection awareness in China. The environmental protection law is provision and foundation, but it should never become an excuse or a guise.

\section{References}

[1] W. Liu, The defects of implementation mechanism of Chinese environmental law and its overcoming, Academic Journal of Zhongzhou,vol.6,pp40-45,2017

[2] Zh. Lü, Thinking on the research of environmental law in the new era, Journal of CUPL,vol.12(4),pp4-14,2018

[3] W. Liu, Environmental law implication of green development concept,Legal Forum,vol.33(6),pp39-47,2018

[4] H. Chen, New normality in environmental protection under the background of green development promotion, China Legal Science,vol, 1,pp69-86,2016

[5] Y.Zhang, Y. Zhang, D. Li, J.Yu and H.Wang, The overview of legal system about recycling plastic packaging material at home and abroad, China Plastics Industry, vol. 39(1),pp1-4,2011 